\title{
Fate or independency: Is batch-specific larval performance determined by egg traits? A case study in farmed pikeperch (Sander lucioperca)
}

Fabian J. Schaefer (1) https://orcid.org/0000-0003-3699-4791, Moritz Tielmann, Julia L. Overton, Angela Krüger, Sven Wuertz, Werner Kloas (1D https://orcid.org/0000-0001-8905-183X, Carsten Schulz, Stefan Meyer

DOI

10.1007/s10499-019-00356-8

Original publication date

12 March 2019 (First Online)

Document version

Author's accepted manuscript version

Published in

Aquaculture International

\section{Citation}

Schaefer FJ, Tielmann M, Overton JL, Krüger A, Wuertz S, Kloas W, et al. Fate or independency: is batch-specific larval performance determined by egg traits? A case study in farmed pikeperch (Sander lucioperca). Aquaculture International. 2019;27(4):957-69. 
1 Fate or independency: Is batch-specific larval performance determined by egg traits? A case

2 study in farmed pikeperch (Sander lucioperca)

3

4 Fabian J. Schaefer ${ }^{1 *}$, Moritz Tielmann ${ }^{2,3}$, Julia L. Overton ${ }^{4}$, Angela Krüger ${ }^{5}$, Sven Wuertz ${ }^{1,6}$, Werner

$5 \quad$ Kloas ${ }^{1,6,7}$, Carsten Schulz ${ }^{2,3}$, Stefan Meyer $^{2}$

6

$7 \quad{ }^{1}$ Department of Ecophysiology and Aquaculture, Leibniz-Institute of Freshwater Ecology and Inland

8 Fisheries, Berlin, Germany

$9 \quad{ }^{2}$ Gesellschaft für Marine Aquakultur, Hafentörn 3, 25761 Büsum, Germany

$10{ }^{3}$ Institute of Animal Breeding and Husbandry, Marine Aquaculture, Christian-Albrechts-University,

11 Kiel, Germany

$12 \quad{ }^{4}$ AquaPri Denmark A/S, Egtved, Denmark

$13{ }^{5}$ Department of Chemical Analytics and Biogeochemistry, Leibniz-Institute of Freshwater Ecology and 14 Inland Fisheries, Berlin, Germany

$15{ }^{6}$ Thaer Institute of Agricultural and Horticultural Sciences, Faculty of Life Sciences, Humboldt

16 University Berlin, Berlin, Germany

$17{ }^{7}$ Institute of Biology, Faculty of Life Sciences, Humboldt University Berlin, Berlin, Germany

18

19

$20 *$ Corresponding author: Fabian J. Schaefer, Department of Ecophysiology and Aquaculture, Leibniz-

21 Institute of Freshwater Ecology and Inland Fisheries, Müggelseedamm 310, 12587 Berlin, Germany. E-

22 mail: schaefer@igb-berlin.de 


\section{Abstract}

Fish embryos and larvae undoubtedly depend on maternal provisioning of essential egg components, such as fatty acids (FA), during early ontogeny. But which aspects and stages of batch-specific larval development are modulated by these inherent oocyte traits? This question is of major importance from an ecological, as well as from an aquacultural perspective. We examined the effects of batch-specific non nuclear-genetic egg traits (fatty acid (FA) profiles, egg size, mtDNA fragmentation, cortisol content) already in unfertilized oocytes of pikeperch (Sander lucioperca) and studied their influence on survival (15 dph) and larval performance (length at hatch, stress resistance, first feeding, swimbladder inflation rate, yolk sac and lipid droplet size, growth in weight and length) after hatching under stable laboratory conditions ( $n=12$ batches). While larval survival and performance were independent of mtDNA fragmentation and cortisol levels, FA profiles affected specific larval traits. Especially FA of the neutral fraction were positively correlated with larval size and growth $(16: 0,18: 0,22: 1 \mathrm{n}-9$, total saturated FA), swimbladder inflation (arachidonic acid 20:4n-6, total FA) and early first feeding (16:0, 18:0, total saturated FA). Important FA of the polar fraction included 15:0 and 16:1n-7, which showed alternate effects on larval survival, first feeding and growth (length). Furthermore, larval length at hatch was positively correlated with egg diameter. Other larval parameters (yolk sac and lipid droplet size and stress response) were not or only marginally affected by egg traits. Consequently, high oocyte FA deposition fuels fast rates of growth and development during early ontogeny. On the other hand, larvae develop independently of assumed disadvantageous properties (cortisol content, mtDNA damage).

Knowledge of this relation allows for the improvement of aquaculture practice, as well as predicting recruitment success in the wild. reproduction 
48 List of abbreviations:

49 ARA arachidonic acid

50 BW body weight

51 DHA docosahexaenoic acid

52 dph day post hatch

53 EPA eicosapentenoic acid

54 FA fatty acid

55 FAME fatty acid methyl esters

56 HUFA highly unsaturated fatty acid

57 MUFA monounsaturated fatty acid

58 SBI swim bladder inflation

59 SD standard deviation

60 SFA saturated fatty acid

61 SL standard length

62 


\section{Introduction}

The postulation omne vivum ex ovo - every living thing comes from an egg - is a fundamental principle of life science. However, not every egg develops into a living organism. This is in particular the case in animals, which produce large amounts of eggs, such as most fish species, to cope with high mortalities especially during early ontogeny. In pikeperch (Sander lucioperca) for example, a pikeperch female can produce more than 400,000 eggs per kg body weight (Lappalainen et al. 2003). Furthermore, larval performance, e.g., size and growth, as well as resistance towards stress and food scarcity, are important modulating factors beyond sheer survival being of major interest for fish ecology and fisheries management, as well as from an aquacultural perspective.

Factors modulating early ontogenetic survival and development are both, external and internal. In addition to predation and fertilization failure caused by low sperm quality or quantity, fish eggs and larvae are exposed to a variety of threats, such as insufficient nutritional reserves and starvation, disease, e.g., fungal infections, predation, varying environmental conditions, e.g., suboptimal temperature or oxygen supply, as well as mechanical injuries or drift (e.g., Feiner and Höök 2015). Furthermore, developing embryos and larvae may suffer from suboptimal inherent (internal) conditions, such as stress or insufficient nutrition, which are transferred from the parents to the offspring (e.g., Brooks et al. 1997; Izquierdo et al. 2001; Bobe and Labbé 2010). Such perturbation may lead to critical levels of adverse detergents or damage within the egg further impeding or even disabling successful development.

Albeit the occurrence of parental care, for example in form of mouth-breeding, nest building or - as in the case of pikeperch - nest guarding, the offspring appear to be most often left alone after spawning or latest after hatching (Feiner and Höök 2015). However, the offspring is not entirely unprepared to face these challenges. Besides nuclear-genetic information, the parents - especially the females - invest substantial resources ideally providing optimum 'start-up' conditions for each embryo while producing large number of eggs to account for inevitable mortalities (Lubzens et al.2010). These resources fuel successful embryogenesis and hatching, as well as enable the larvae to cope with suboptimal conditions, e.g., sufficient nutrients stored in the yolk-sac to resist starvation until sufficient prey becomes available. 
In an aquaculture setting, farmers may benefit from this reproductive strategy. By providing optimal conditions in the absence of inter-species and inter-cohort predation or cannibalism during egg incubation and larval rearing, one could expect high numbers of offspring from a limited number of well-conditioned spawners. Still, mortalities occur or larval performance may be poor, which cannot be solely explained by disease, suboptimal rearing or intra-cohort cannibalism (Feiner and Höök 2015). Indeed, the reliable production of high quality larvae is to date a major bottleneck and mortalities during early life-stages remain high, especially in candidate species such as pikeperch (Overton et al. 2015; Schaerlinger and Žarski 2015).

To date, only a limited number of studies observed the influence of batch-specific egg traits on larval performance parameters under stable and presumably optimal rearing conditions. We addressed this topic in eggs and larvae of pikeperch, a freshwater predator with a large distribution in Europe (Lappalainen et al. 2003). The species does not only sustain substantial inland fisheries, both commercial and recreational, but is also considered as a prime candidate for European inland aquaculture diversification (Mylonas and Robles 2014). Here, batch-specific larval performance was observed in rearing experiments and related to egg characteristics, which have been determined in subsamples of unfertilized oocytes. The performance parameters consisted of the fundamental life-history traits size and growth, as well as survival. In addition, yolk and lipid droplet size, as quantitative measures of nutritional reserves, swimbladder inflation rate, day of first feeding, and stress resistance (salinity change) were determined. Egg parameters considered were fatty acid (FA) profiles and egg size, as well as mtDNA lesion rates and cortisol levels as potentially harmful traits.

Especially the FA are acknowledged as integrative parameters modulating several aspects of early life-history (Dabrowski et al. 2015; Kestemont and Henrotte 2015; Schaerlinger and Žarski 2015). The FA, especially the highly unsaturated FA (HUFA) are important structural components, serve as nutrient reserves and are precursors of eicosanoids (Bell et al. 1986; Tocher 2003). In developing pikeperch embryos, specific FA are related to fertilization success and survival (Schaefer et al. 2018a). Egg size on the other hand is often related to a larger size at hatch, which in turn is supposed to be beneficial for 
115 larval survival in a natural environment (Brooks et al. 1997). During embryogenesis in incubated eggs

116 however, size proved to have adverse effects on development in pikeperch, whereas embryos gained

117 increasing independence from the inherent egg composition until hatching (Schaefer 2016; Schaefer et

118 al. 2018a). Still, it appears likely that these traits come into effect after hatching modulating larval

119 performance. The neutral FA fraction for example, which is predominantly stored within the oil globule

120 and not mobilized during embryogenesis, is likely to affect larval performance parameters after hatch

121 prior to first feeding (Wiegand 1996; Žarski et al. 2012). It was shown in free swimming percid larvae

122 that life-traits, e.g., susceptibility towards stress, are modulated by specific HUFA (Henrotte et al.

123 2010). However, these studies observed effects of alternating nutritional FA levels and knowledge of the

124 influence of inherent FA profiles is scarce.

125 Consequently, specific aspects of the inherent egg characteristics may well be stage- and/or traitspecific. Knowledge of egg components, which - positively or negatively - modulate larval

127 performance, as well as ontogenetic effect strength, can support optimization of farming protocols. In parallel, information on the level of predetermination of batch- and stage-specific development may contribute to fisheries management in terms of prediction of recruitment success. Here, we present the combined analysis of data obtained by a two-part project, which aimed at understanding broodstock

131 effects on gamete quality (Schaefer et al. 2018a,b) and on larval performance (Tielmann, 2017).

\section{Material and Methods}

2.1 Fish origin and egg sampling

135 All egg batches $(n=12)$ were sampled at a commercial aquaculture facility (AquaPri, Egtved,

Denmark) during routine reproduction procedures in accordance with EU and National legislation for animal welfare in fish production. AquaPri maintained four separated, seasonally shifted, but otherwise identically reared broodstocks of the same genetic origin to achieve four spawning seasons per year

139 (intervals of three months). Spawning was induced once per year in each broodstock using an identical protocol. After four months of wintering below $14{ }^{\circ} \mathrm{C}$ the temperature was raised to $\sim 16^{\circ} \mathrm{C}$ for the 
141 induction of natural ovulation (no hormone treatment). The samples of the present study were obtained 142 during two consecutive years including six different spawning seasons from a total of twelve individual 143 females. Average female size (measured to the nearest $\mathrm{cm}$ ) was $69.5 \mathrm{~cm}$ ranging from 63.0 to $78.0 \mathrm{~cm}$.

144 After introduction to the broodstock, all females were allowed to acclimatize for a full annual cycle

145 before being stripped for the first time. Prior to stripping, spawners were anesthetized (Kalmagin 20\%;

146 Centrovet, Santiago de Chile, Chile). Sub-samples of unfertilized eggs were taken, transported to the 147 laboratory in liquid nitrogen and stored at $-80^{\circ} \mathrm{C}$ until analyses. The remaining majority of eggs were

148 fertilized according to the hatchery protocol using one to three different running males (in vitro

149 fertilization, depending on the availability of running males). Fertilization rates observed $\sim 2 \mathrm{~h}$ post-

150 fertilization ranged from 85.0 to $98.0 \%$ with an average of $92.1 \%$ fertilized eggs confirming

151 functionality of the protocol. Fertilized eggs were transferred to Zuger-jars and incubated at 15 to $16{ }^{\circ} \mathrm{C}$.

152 Hatching rates (all eggs and not only fertilized eggs taken into account) were $86.9 \%$ on average with a 153 minimum of $71.2 \%$ hatched larvae per batch. Large portions of the fertilized eggs were transported to 154 the experimental rearing facilities after 10 to 40 degree days $\left(\mathrm{d}^{\circ} \mathrm{C}\right)(\mathrm{cf} .2 .3)$.

155

\subsection{Egg parameter analyses}

157 Egg FA analysis was performed in ten out of twelve batches according to the protocol by Boëchat et al.

158 (2014) with changes described by Schaefer et al. (2018a). In brief, FA were extracted from

159 homogenized eggs after dry-freezing with chloroform-methanol $(2: 1 \mathrm{~V}: \mathrm{V})$. Neutral and polar lipids

160 were separated by solid phase extraction using Strata NH2 (55 $\mu \mathrm{m} ; 70 \AA$ ) $1000 \mathrm{mg} / 6 \mathrm{~mL}$ columns

161 (Phenomenex, Torrance, CA, USA). After methylation of each fraction, the re-suspended FA methyl

162 esters (FAME) were analyzed in an Agilent 6890N gas chromatograph (Agilent, Santa Clara, CA, USA)

163 equipped with an Agilent 5973N mass selective detector (Agilent) and a fused silica capillary column

164 (J\&W CP-Sil 88 for FAME; Agilent). Detection limit was $0.1 \mu \mathrm{g} \mathrm{mg}^{-1}$ and determination threshold was

$1650.4 \mu \mathrm{g} \mathrm{mg}^{-1}$. Specific FA below quantification limit were excluded from further analyses. Egg size was

166 determined for 10 eggs per batch using ImageJ software (version 1.44; National Institute of Health, 
USA). Egg cortisol content of $30 \mu 1$ manually crushed eggs were analyzed in duplicate using a cortisolspecific enzyme-linked immunosorbent assays (ELISA; IBL, Hamburg, Germany) according to Hermelink et al. (2011). A dilution series was used to calculate cortisol concentrations. Determined recoveries (spiking experiment) exceeded 91\%. Mitochondrial DNA (mtDNA) fragmentation for two mtDNA regions (12S, cytochrome B) was assessed by qPCR according to Schaefer et al. (2016). Specifications of the qPCR assays are displayed in table 1. Lesion rates were calculated as described by Rothfuss et al. (2010).

\subsection{Egg incubation and larval rearing}

Egg incubation and larval rearing protocols are described in detail by Tielmann (2017). In brief, fertilized eggs of 12 females were transported to the rearing facilities after 10 to $40 \mathrm{~d}^{\circ} \mathrm{C}$ at $16-17^{\circ} \mathrm{C}$ over the course of two years. Eggs were incubated at the experimental facility of the Gesellschaft für Marine Aquakultur (GMA; Büsum, Germany) in McDonald-type hatching jars (Pentair Hatching Jar, Apopka, United States) at $18{ }^{\circ} \mathrm{C}$ and $50 \mathrm{~lx}$ ambient light. Stopping the water inflow after $72 \mathrm{~d}^{\circ} \mathrm{C}$ induced hatching. Larvae were stocked into $40 \mathrm{~L}$ tanks in triplicates at a density of 100 larvae $\mathrm{L}^{-1}$ and a temperature of $18 \pm 0.5^{\circ} \mathrm{C}(n=12,000$ larvae per batch). Water turbidity was maintained at $2-5$

Nephelometric Turbidity Units (NTU) using algae concentrate (BlueBioTech Nannochloropsis sp., Büsum, Germany). Light (24 h) was provided by light tubes (Lampen XXL CMI T 36W IP 65, Kronau, Germany) with an intensity of 500-700 1x. From 4 days post hatch (dph) onwards, larvae were fed Artemia spec. nauplii (INVE AF Specialty Cysts, Dendermond, Belgium) at a density of 10 nauplii $\mathrm{ml}^{-1}$ every $6 \mathrm{~h}$ until the end of experiment at $21 \mathrm{dph}$.

\subsection{Larval performance parameters}

The sampling for the assessment of larval performance parameters started immediately at 0 dph every 3 days until $21 \mathrm{dph}$. Sampling took place between 2 and 4 pm on each sampling day (after second feeding). Per sampling, 30 larvae (10 larvae from each rearing tank) were transferred into a solution of 
$193 \mathrm{pH}$-stabilized tricaine methansulfonate (MS222) for sedation. Images of sedated larvae were taken

194 (Olympus SZ61, Tokio, Japan). Afterwards, the larvae were rinsed under deionized water, individually

195 stored in $1.5 \mathrm{ml}$ Eppendorf tubes and snap-frozen at $-80{ }^{\circ} \mathrm{C}$.

196 Standard length (SL; tip of the upper jaw to the posterior end of the last vertebra), yolk-sac size and

197 lipid-droplet size (both at $0 \mathrm{dph}$ ) were determined from the images using ImageJ software. For the

198 determination of body weight (BW), frozen larvae were freeze-dried for $24 \mathrm{~h}$ (Christ Alpha LD 1-2,

199 Osterode, Germany) and individually weighed (Sartorious Cubis Balance MSA2.7S, Göttingen,

200 Germany). Average sizes (SL and BW) of larvae were combined per sampling day for the calculation of

201 respective growth parameters (slope and intercept of the growth curve). Growth in SL and BW followed a natural exponential curve with size $_{\text {time }}=$ intercept $^{*} e^{(\text {slope*time) }}$. The proportion of swim bladder inflation

203 (SBI) was recorded after 15 dph for the 30 larvae sampled per batch.

Day of first feeding (50\% of larvae with visible food ingestion) was determined by observing the 205 gut fullness of 30 randomly selected larvae from 3 dph onwards. On day 15 post hatch total number of larvae in each tank were counted to calculate the survival rate taking sampled larvae into account $(n=$ 4,000 larvae tank $\mathrm{k}^{-1}$ at $0 \mathrm{dph}$ ). On the same day, a stress test was conducted by exposing larvae to an acute salinity challenge. A total of 360 larvae (120 from each tank) were transferred to a $1 \mathrm{~L}$ glass beaker containing saltwater (19 PSU; $18^{\circ} \mathrm{C}$ ). Cumulative mortality (larvae lying motionless on the bottom) was determined over a period of $2 \mathrm{~h}$ in intervals of $5 \mathrm{~min}$ as described by Dagar et al. (2010).

213 Data are presented as mean \pm standard deviation (SD). Correlation analysis was performed with Spearman's correlation using SPSS (version 22; IBM, Armonk, NY, USA). Due to a lack of data (missing sampling points) not all larval performance parameters could be assessed for all 12 batches.

216 For specific parameters (growth curves, rates of survival, SBI, stress test survival) only 9 datasets were 217 available for correlation analysis. 


\section{Results}

\subsection{Egg and larval parameters}

Egg FA profiles for the ten observed egg batches of both, neutral and polar fractions, are presented in table 2. The mtDNA lesion rates for the two tested genes were $2.0 \pm 2.2$ for $12 \mathrm{~S}$ ranging from 0 to 5.9 and $0.6 \pm 0.1$ for cytochrome B with a minimum of 0.5 and a maximum of 0.8 lesions per $10 \mathrm{kbp}$. Egg cortisol level was $78.2 \pm 31.0 \mathrm{ng} \mathrm{mL}^{-1}$ on average with 37.0 as lowest and $134.7 \mathrm{ng} \mathrm{mL}^{-1}$ as highest observed concentration. Average egg diameter was $1.2 \pm 0.1 \mathrm{~mm}$ ranging from 1.0 to $1.3 \mathrm{~mm}$. Larval parameters are listed in table 3.

\subsection{Links between egg and larval parameters}

Correlation analysis showed links between larval performance after hatch and egg parameters (table 2). Especially the FA profile affected the larvae. Interestingly, only 15:0 and 16:1n-7 of the polar FA fraction showed linkage with larval performance whereas a variety of FA of the neutral fraction, including ARA, were involved in modulating larval traits. If the polar FA affected standard length growth parameters, the neutral ones were correlated with larval weight gain. Within the polar fraction, 15:0 and $16: 1 \mathrm{n}-7$ seem to have alternating effects. Where $15: 0$ was positively correlated with larval parameters, 16:1n-7 had a negative relation and the other way around. The only larval trait which was not significantly correlated with any egg parameters was the lipid-droplet size. There were no correlations found in regard to egg cortisol levels and mtDNA damage. Egg diameter however, was correlated not only with larval standard length at hatch (Fig. 1) and growth, but was also associated with swimbladder inflation rate.

\section{Discussion}

The influence of broodstock properties, such as individual size, age, nutritional status and stress, and their effect on egg composition has been studied in numerous fish species including percids (Schreck et al. 2001; Kestemont and Henrotte 2015). On the other hand, there is only very little information 
available on how variability in inherent batch-specific egg traits is related to early larval performance after hatch under similar conditions. In previous efforts we could - to a certain extent - identify a critical modulating role of FA profiles, mainly of FA within the polar fraction, during the first $48 \mathrm{~h}$ post fertilization in pikeperch (Schaefer et al. 2018a). This influence however, was of lesser significance during late embryo development and hatching. It was hypothesized that specific egg traits, mainly FA of the neutral fraction, may exert a strong influence on larval performance after hatch due to the conservation of these components during early embryogenesis (Moodie et al. 1989; Wiegand 1996). Presence of such modulating effects of FA, especially HUFA, during early ontogeny is supported by observations made in other percids (Henrotte et al. 2010; Lund and Steenfeldt 2011). Therefore, the analysis of the effects of inherent egg traits was extended beyond the critical hatching stage. Indeed, we could detect correlations between FA of the neutral fraction (16:0, 18:0, SFA) and important early life history traits, especially in regard to growth and size characteristics. High deposition of specific FA also induced advanced first feeding. Levels of ARA and total FA positively affected SBI. Consequently, specific larval capabilities seem to be pre-determined by the inherent egg composition, which could be detected prior to fertilization. The importance of FA during reproduction and early ontogeny was studied and described for a variety of fish species including percids (e. g., Czesny and Dabrowksi 1998; Dabrowski et al. 2015; Kestemont and Henrotte 2015). In Eurasian perch (Perca fluviatilis), modulating effects of dietary FA on the broodstock levels could be detected, which were reflected in the FA composition of the eggs (Henrotte et al. 2010). Especially the levels and composition of HUFA are of major importance during early development. Here, ARA was positively correlated with SBI. At 15 dph it is most likely that the critical phase of SBI had ended (Steenfeldt 2015). Arachidonic acid is the main precursor of eicosanoids, which are in turn essential for embryonic development. (Bell et al. 1986; Sargent et al. 2002; Tocher 2003). Interestingly, we did not detect critical influence of other HUFA. It is likely, that onset of external feeding from 3 dph onwards may have masked these effects. It was shown for pikeperch larvae that varying HUFA composition in larval diets from 3 to $21 \mathrm{dph}$ affect larval performance (Lund and Steenfeldt 2011). 
On 15 dph the larvae were exposed to an acute salinity challenge to test for the capabilities to perform osmoregulation and to counteract stress (Kestemont et al. 2007; Lund and Steenfeldt 2011;

273 Lund et al. 2012). While batch-specific survival rates were highly variable, the capabilities were only marginally correlated with egg FA profiles and were thus relatively independent of the observed traits. Interestingly, Tielmann (2017) observed a strong and significant link between lipid-droplet size and stress test survival in pikeperch larvae and hypothesized that this might be due to the availability of MUFA, which are primarily stored in the oil droplet in larvae of teleost fish (Wiegand 1996; Schaerlinger and Žarski 2015). In Eurasian perch Henrotte and colleagues (2010) observed differences in osmotic stress tolerance in larvae depending on the HUFA levels in the broodstock diet, which was reflected in the egg composition. Such patterns could not be confirmed by the findings of the present study.

Not all egg traits, which showed significant correlations with larval performance, proofed to be advantageous for the developing larvae. Especially the composition of FA within the polar fraction had inconsistent impacts. For example, the growth intercept of the SL was positively correlated with 15:0 and negatively correlated with $16: 1 \mathrm{n} 7$. It is documented that an excess of specific FA can exert negative effects during early ontogeny (Fernández-Palacios et al. 1995; Broach et al. 2017; Schaefer et al. 2018a). Yet, it is not clear which underlying patterns may explain for these observed counteracting effects. The indicative or predictive value of FA regarding egg and larval quality are somewhat limited due to high variability and might not be generalized (Schaerlinger and Žarski 2015).

In addition to FA profiles, morphometric traits are among the first parameters to be studied in relation to egg and larval characteristics. Several studies explored the relations involved in egg size and developmental success, but there seems to be no generally valid pattern (Brooks et al. 1997; Kamler 2005). Positive effects of large egg sizes have often been associated with a larger larval size at hatch and an optimized nutritional state of the embryo. In turn, sizes at hatch were correlated with growth and survival of larvae and juveniles in the field (Meekan and Fortier 1996; Benôit and Pepin 1999) and in laboratory studies (Trippel et al. 2005). Indeed, we detected a positive correlation of larval SL at hatch 
and egg diameter, which was well in range of previous reports on pikeperch oocytes prior to fertilization (Demska-Zakes et al. 2005; Žarski et al. 2012). In addition, elevated egg size was associated with increased SBI at $15 \mathrm{dph}$ further supporting the critical role of size at hatch.

The influence and fate of cortisol during fish reproduction is still being controversially discussed (Milla et al. 2009). There are indications that the initial egg cortisol levels are diluted during the uptake of water (Hwang et al. 1992; Brooks et al. 1997; Stratholt et al. 1997). Here, egg cortisol had no adverse effect, similar to the observations made during embryogenesis (Stratholt et al. 1997; Schaefer et al. 2017). While larval performance was independent of egg cortisol content, it was shown that the FA profiles are linked to this primary stress marker in pikeperch oocytes, which in turn could potentially affect early ontogeny (Schaefer et al. 2018a). Similar to cortisol, the detected mtDNA fragmentation had no visible effect on larval traits. The mtDNA is a suitable target for the detection of damage induced by reactive oxygen species since it is more prone to fragmentation compared to the nuclear DNA (Sawyer et al. 2003). It seems that either potent repair mechanisms (Rothfuss et al. 2010; Alexeyev et al. 2013) or partial degradation of damaged DNA (Alexeyev et al. 2013) prevented adverse effects as discussed by Schaefer et al. (2016) for pikeperch embryos.

As observed in a previous study, the variability in egg traits was relatively high (Schaefer et al. 2018a). This pattern could be followed into the larval stage here. Such differences and variability in egg composition may arise from a variety of extrinsic and intrinsic factors including stress, nutrition, nuclear and non-nuclear genetic information, female size, age, spawning experience and condition or individual metabolism, as well as environmental conditions (e.g., Schreck et al. 2001; Kestemont and Henrotte 2015; Schaefer et al. 2018b). In addition, fertilization success and offspring performance is also influenced by sperm traits (Bobe and Labbé 2010). However, the offspring seem to be able to cope with a variety of inherent characteristics including potentially harmful ingredients or damage. In the context of the high variability observed here, the detected correlations of specific traits may highlight crucial characteristics. 
324 In this case study, we have discovered a relatively high level of independency for the observed batchspecific larval performances in response to the inherent egg traits under similar and seemingly ideal conditions. However, specific aspects -in regard to FA profiles and egg size - were associated with early larval characteristics. Consequently, high oocyte FA deposition (neutral fraction) fuels fast rates of growth and development during early ontogeny after hatch. On the other hand, larvae developed independently of assumed disadvantageous properties (cortisol content, mtDNA damage). Knowledge of this relation allows for the improvement of aquaculture practice, e. g. in terms of early larval and broodstock feed formulation, as well as predicting recruitment success in the wild.

\section{Acknowledgements}

This study was funded by the German Research Foundation (DFG KL 745/6-1 and SCHU 2308/3-2).

We would like to thank our cooperation partner AquaPri and the members of the IGB and GMA, who have supported this study.

Conflict of Interest: The authors declare that they have no conflict of interest.

Ethical approval: Fish rearing and reproduction were performed in accordance with EU and National legislation for animal welfare in fish production.

\section{References}

Alexeyev M, Shokolenko I, Wilson G, LeDoux S (2013) The Maintenance of Mitochondrial DNA Integrity-Critical Analysis and Update. Csh Perspect Biol 5

Bell MV, Henderson RJ, Sargent JR. The role of polyunsaturated fatty acids in fish (1986) Comp Biochem Physiol 83:711-719 
Benôtt HP, Pepin P (1999) Interaction of rearing temperature and maternal influence on egg development rates and larval size at hatch in yellowtail flounder (Pleuronectes ferrugineus). Can J Fish Aquat Sci 56:785-794

Bobe J, Labbé C (2010) Egg and sperm quality in fish. Gen Comp Endocrinol 165:535-548

Boëchat IG, Krüger A, Chaves RC, Graeber D, Gücker B (2014) Land-use impacts on fatty acid profiles of suspended particulate organic matter along a larger tropical river. Sci Total Environ 482:62-70

Broach JS, Ohs CL, Breen NE (2017) Protracted volitional spawning of pinfish Lagodon rhomboides and changes in egg quality and fatty-acid composition throughout the spawning season. J Fish Biol $91: 806-817$

Brooks S, Tyler CR, Sumpter JP (1997) Egg quality in fish: what makes a good egg? Rev Fish Biol Fisher 7:387-416

Czesny S, Dabrowski K (1998) The effect of egg fatty acid concentrations on embryo viability in wild and domesticated walleye (Stizostedion vitreum). Aquat Living Resour 11:371-378

Dabrowski K, Rinchard J, Czesny S, Korzeniowska M (2015) Effects of Dietary Levels of PUFA Fed to Adult Yellow Perch on the Fatty Acid Composition of Eggs and Larvae Characteristics: New Research Directions. In: Kestemont P, Dabrowski K, Summerfelt RC (eds) Biology and Culture of Percid Fishes, Springer, Dordrecht, pp 565-586.

Dagar A, Zilberg D, Cohen Z, Boussiba S, Khozin-Goldberg I (2010) Short-term dietary supplementation with the microalga Parietochloris incisa enhances stress resistance in guppies Poecilia reticulata. Aquacult Res 41:267-277

Demska-Zakes K, Zakes Z, Roszuk J (2005) The use of tannic acid to remove adhesiveness from pikeperch, Sander lucioperca, eggs. Aquacult Res 36:1458-1464

Feiner ZS, Höök TO (2015) Environmental Biology of Percid Fishes. In: Kestemont P, Dabrowski K, Summerfelt RC (eds) Biology and Culture of Percid Fishes, Springer, Dordrecht, pp61-100 
372 Fernández-Palacios H, Izquierdo MS, Robaina L, Valencia A, Salhi M, Vergara JM (1995) Effect of n-

3733 HUFA level in broodstock diets on egg quality of gilthead sea bream (Sparus aurata L.).

$374 \quad$ Aquacultu 132:325-337

375 Henrotte E, Mandiki RSNM, Prudencio AT, Vandecan M, Mélard C, Kestemont P (2010) Egg and

376 larval quality, and egg fatty acid composition of Eurasian perch breeders (Perca fluviatilis) fed

377 different dietary DHA/EPA/AA ratios. Aquacult Res 41:53-61

378 Hermelink B, Wuertz S, Trubiroha A, Rennert B, Kloas W, Schulz C (2011) Influence of temperature

379 on puberty and maturation of pikeperch, Sander lucioperca. Gen Comp Endocrinol 172:282-292

380 Hwang PP, Wu SM, Lin JH, Wu LS (1992) Cortisol content of eggs and larvae of teleosts. Gen Comp

$381 \quad$ Endocrinol 86:189-196

382 Izquierdo MS, Fernández-Palacios H, Tacon AGJ (2001) Effect of broodstock nutrition on reproductive

383 performance of fish. Aquacult 197:25-42

384 Kamler E (2005) Parent-egg-progeny relationships in teleost fishes: an energetics perspective. Rev Fish $385 \quad$ Biol Fish 15:399-421

386 Kestemont P, Xu XL, Hamza N, Maboudou J, Toko II (2007) Effect of weaning age and diet on 387 pikeperch larviculture. Aquacult 264:197-204

388 Kestemont P, Henrotte E (2015) Nutritional Requirements and Feeding of Broodstock and Early Life

389 Stages of Eurasian Perch and Pikeperch. In: Kestemont P, Dabrowski K, Summerfelt RC (eds)

390 Biology and Culture of Percid Fishes, Springer, Dordrecht, pp 539-564

391 Lappalainen J, Dörner H, Wysujack K (2003) Reproduction biology of pikeperch (Sander lucioperca

392 (L.)) - a review. Ecol Freshw Fish 12:95-106

393 Lubzens E, Young G, Bobe J, Cerda J (2010) Oogenesis in teleosts: how fish eggs are formed. Gen

$394 \quad$ Comp Endocrinol 165:367-389

395 Lund I, Steenfeldt SJ (2011) The effects of dietary long-chain essential fatty acids on growth and stress

396 tolerance in pikeperch larvae (Sander lucioperca L.) Aquacult Nutr 17:191-199 
Lund I, Skov PV, Hansen BW (2012) Dietary supplementation of essential fatty acids inlarval pikeperch (Sander lucioperca); short and long term effects on stress tolerance and metabolic physiology. Comp Biochem Phys A 162:340-348

Meekan MG, Fortier L (1996) Selection for fast growth during the larval life of Atlantic cod Gadus morhua on the Scotian Shelf. Mar Ecol Prog Ser 137:25-37

Milla S, Wang N, Mandiki SNM, Kestemont P (2009) Corticosteroids: Friends or foes of teleost fish reproduction? Comp Biochem Physiol 153:242-251

Moodie GEE, Loadman NL, Wiegand MD, Mathias JA (1989) Influence of egg characteristics on survival, growth and feeding in larval walleye (Stizostedion vitreum). Can J Fish Aquat Sci 46:516521

Mylonas CC, Robles R (2014) Removing production bottlenecks of emerging species for European aquaculture. Aquaculture Europe 39:5-15

Overton JL, Toner D, Poliçar T, Kucharczyk D (2015) Commercial Production: Factors for Success and Limitations in European Percid Fish Culture. In: Kestemont P, Dabrowski K, Summerfelt RC (eds) Biology and Culture of Percid Fishes. Springer, Dordrecht, pp 881-890

Rothfuss O, Gasser T, Patenge N (2010) Analysis of differential DNA damage in the mitochondrial genome employing a semi-long run real-time PCR approach. Nucleic Acids Res 38

Sargent JR, Tocher DR, Bell JG (2002). The lipids. In: Halver JE, Hardy RW (eds) Fish Nutrition, 3rd edn. Academic press, San Diego, pp 181-257

Sawyer DE, Mercer BG, Wiklendt AM, Aitken RJ (2003) Quantitative analysis of gene-specific DNA damage in human spermatozoa. Mutat Res-Fund Mol M, 529:21-34

Schaefer FJ (2016) Reproductive management and gamete quality in pikeperch (Sander lucioperca). Dissertation, Humboldt-Universität zu Berlin

Schaefer FJ, Overton JL, Wuertz S (2016) Pikeperch Sander lucioperca egg quality cannot be predicted by total antioxidant capacity and mtDNA fragmentation. Anim Rep Sci 167:117-124 
Schaefer FJ, Overton JL, Krüger A, Kloas W, Wuertz S (2018a) Influence of batch-specific biochemical egg characteristics on embryogenesis and hatching success in farmed pikeperch. Animal 12:23272334

Schaefer FJ, Overton JL, Kloas W, Wuertz S (2018b) Length rather than year-round spawning, affects reproductive performance of RAS-reared F-generation pikeperch, Sander lucioperca (Linnaeus, 1758) - Insights from practice. J Appl Ichthyol 34:617-621

Schaerlinger B, Żarski D (2015) Evaluation and Improvements of Egg and Larval Quality in Percid Fishes. In: Kestemont P, Dabrowski K, Summerfelt RC (eds) Biology and Culture of Percid Fishes, Springer, Dordrecht, pp 193-226

Schreck CB, Contreras-Sanchez W, Fitzpatrick MS (2001) Effects of stress on fish reproduction, gamete quality, and progeny. Aquacult 197:3-24

Steenfeldt S. (2015) Culture Methods of Pikeperch Early Life Stages. In: Kestemont P, Dabrowski K, Summerfelt RC (eds) Biology and Culture of Percid Fishes, Springer, Dordrecht, pp 295-312

Stratholt ML, Donaldson EM, Liley NR (1997) Stress induced elevation of plasma cortisol in adult female coho salmon (Oncorhynchus kisutch), is reflected in egg cortisol content, but does not appear to affect early development. Aquacult 158:141-153

Tielmann M (2017) The effect of out-of-season production and light regime manipulation for intensive pike-perch (Sander lucioperca) larvae culture. Dissertation, Kiel University

Tocher DR (2003) Metabolism and functions of lipids and fatty acids in teleost fish. Rev Fish Sci $11: 107-184$

Trippel EA, Kraus G, Köster FW (2005) Maternal and paternal influences on early life history traits and processes of Baltic cod Gadus morhua. Mar Ecol Prog Ser 303:259-267

Wiegand MD (1996) Composition, accumulation and utilization of yolk lipids in teleost fish. Rev Fish Biol Fish 6:259-286 
446 Žarski D, Kucharczyk D, Targonska K, Palinska K, Kupren K, Fontaine P, Kestemont P (2011) A new

447 classification of pre-ovulatory oocyte maturation stages in pikeperch, Sanderlucioperca (L.), and its 448 application during artificial reproduction. Aquacult Res 43:713-721

449 
450

451 Fig. 1. Egg diameter versus larvae standard length at hatch $(n=12)$.

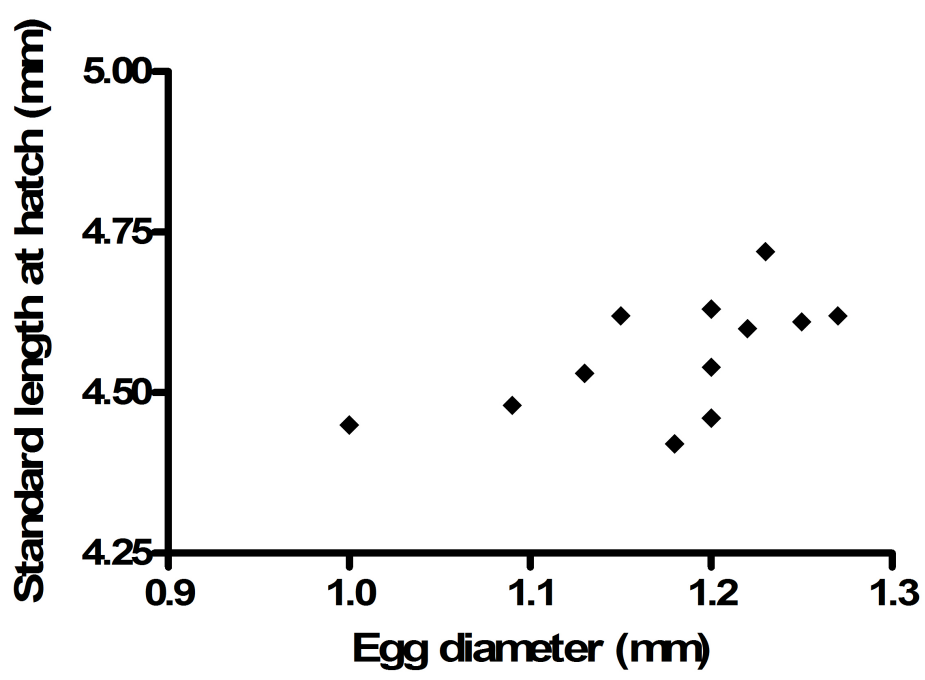

452

453

454 Tables

455

456 Table 1. Specifications of qPCR assays targeting short (s) and long (1) segments of the 12S and

457 cytochrome B (cytb) genes for the determination of lesion rates per $10 \mathrm{~kb}$. The table includes primer

458 sequences, amplicon length in base pairs (bp) and qPCR efficiency (Eff). Annealing temperature was 60

$459{ }^{\circ} \mathrm{C}$ for all targets.

\begin{tabular}{|c|c|c|c|c|}
\hline $\begin{array}{c}\text { Target gene } \\
\text { (fragment) }\end{array}$ & Primer & 5'-3' sequence & $\begin{array}{l}\text { Size } \\
\text { [bp] }\end{array}$ & $\begin{array}{c}\text { Eff } \\
{[\%]}\end{array}$ \\
\hline \multirow[t]{2}{*}{ I12S } & $f$ & GAACTCAGCAGTGATAGACA & 739 & 86.0 \\
\hline & $r$ & GTACACTTACCATGTTACGA & & \\
\hline \multirow[t]{2}{*}{ s12S } & $f$ & GAACTCAGCAGTGATAGACA & 249 & 95.0 \\
\hline & $r$ & CGTAGCTTTCGTGGGTTCAG & & \\
\hline \multirow[t]{2}{*}{ Icytb } & $\mathrm{f}$ & ACAACGCACTAGTTGACCTA & 1066 & 96.5 \\
\hline & $\mathrm{r}$ & GAGAGCCTTGTTTTCAACCCAT & & \\
\hline \multirow[t]{2}{*}{ scytb } & $\mathrm{f}$ & ATGTTCCATTCTTACCTGA & 141 & 96.4 \\
\hline & $r$ & GAGAGCCTTGTTTTCAACCCAT & & \\
\hline
\end{tabular}

460 
462 Table 2. Absolute FA content $\left(\mu \mathrm{g} \mathrm{mg}^{-1} \text { dry weight) and standard deviation (SD) major fatty acids (FA) }\right)^{1}$

463 and selected ratios in polar and neutral FA for ten observed egg batches (prior to fertilization).

\begin{tabular}{|c|c|c|c|c|}
\hline \multirow{2}{*}{$\begin{array}{l}\text { Fatty acid (FA) } \\
14: 0\end{array}$} & \multicolumn{2}{|c|}{$\begin{array}{c}\text { Polar fraction } \\
\text { Mean } \pm \text { SD }\end{array}$} & \multicolumn{2}{|c|}{$\begin{array}{r}464 \\
\text { Neutral fractio } 465 \\
\text { Mean } \pm \mathrm{SD}_{466}\end{array}$} \\
\hline & 1.32 & \pm 0.25 & 2.07 & \pm 0.45467 \\
\hline $15: 0$ & 0.50 & \pm 0.25 & 0.38 & \pm 0.24 \\
\hline $16: 0$ & 9.94 & \pm 2.92 & 12.93 & \pm 2.16 \\
\hline $16: 1(n-7)$ & 0.40 & \pm 0.25 & 10.87 & \pm 4.42 \\
\hline $18: 0$ & 4.06 & \pm 1.82 & 8.37 & \pm 1.55470 \\
\hline $18: 1(n-9)$ & 0.80 & \pm 0.28 & 14.19 & \pm 5.32 \\
\hline $18: 2(n-6)$ & $N / A$ & & 9.93 & $\pm 4.90_{477}$ \\
\hline $18: 3(n-3)$ & N/A & & 1.51 & \pm 0.73 \\
\hline $20: 4(n-6), A^{2} A^{2}$ & N/A & & 1.01 & $\pm 0.42^{4 / 3}$ \\
\hline $20: 5(n-3), E^{3}$ & 0.94 & \pm 0.34 & 6.72 & \pm 3.31 \\
\hline $22: 6(n-3), D^{2} A^{4}$ & 3.35 & \pm 1.49 & 27.27 & \pm 8.71475 \\
\hline Sum SFA ${ }^{5}$ & 16.21 & \pm 4.92 & 23.78 & $\begin{array}{r}476 \\
\pm 3.82\end{array}$ \\
\hline Sum MUFA ${ }^{6}$ & 1.99 & \pm 1.16 & 27.12 & \pm 10.15 \\
\hline Sum n-3 HUFA ${ }^{7}$ & 4.29 & \pm 1.83 & 35.51 & $\begin{array}{r} \pm 12.4778 \\
479\end{array}$ \\
\hline DHA/EPA & 3.47 & \pm 0.39 & 4.36 & \pm 0.91480 \\
\hline EPA/ARA & $N / A$ & & 6.55 & \pm 1.03481 \\
\hline Sum FA & 23.60 & \pm 5.88 & 97.35 & \pm 27.6782 \\
\hline
\end{tabular}

$484{ }^{1}$ Other FA routinely found (below quantification limit of $0.4 \mu \mathrm{g} \mathrm{mg}{ }^{-1}$ dry weight): 12:0, 17:0, 20:0, 20:1(n-9), 20:2

485 (unknown isomer), 22:0, 22:1(n-9), 24:0, 24:1 (unknown isomer).

$486{ }^{2}$ Arachidonic acid.

$487{ }^{3}$ Eicosapentaenoic acid.

$488{ }^{4}$ Docosahexaenoic acid.

$489{ }^{5}$ Saturated fatty acid.

$490{ }^{6}$ Monounsaturated fatty acid.

$491{ }^{7}$ Highly unsaturated fatty acid. 
492 Table 3. Mean \pm standard deviation (SD), minimum (min) and maximum (max) values for larval 493 parameters. Growth characteristics are presented as intercept and slope of the growth curve $\left(\right.$ size $_{\text {time }}=$ 494 intercept* $\left.e^{(\text {slope*time) }}\right)$.

\begin{tabular}{|c|c|c|c|c|c|}
\hline Parameter & Mean & \pm SD & Min & Max & $n$ \\
\hline Survival 15 dph (\%) & 68.20 & \pm 31.14 & 16.33 & 99.33 & 9 \\
\hline Stress test survival $15 \mathrm{dph}(\%)$ & 54.13 & \pm 32.17 & 4.67 & 98.67 & 9 \\
\hline Swimbladder inflation 15 dph (\%) & 39.59 & \pm 26.83 & 0 & 73.33 & 9 \\
\hline Standard length at hatch $(\mathrm{mm})$ & 4.56 & \pm 0.09 & 4.42 & 4.72 & 12 \\
\hline Yolk-sac size $\left(\mathrm{mm}^{2}\right)$ & 0.48 & \pm 0.38 & 0.04 & 1.32 & 12 \\
\hline Lipid-droplet size $\left(\mathrm{mm}^{2}\right)$ & 0.17 & \pm 0.03 & 0.12 & 0.21 & 12 \\
\hline Day at $50 \%$ first feeding & 6.83 & \pm 1.34 & 5 & 10 & 12 \\
\hline Growth $\left(\mathrm{BW}^{1}\right)$ intercept & 0.09 & \pm 0.03 & 0.05 & 0.12 & 9 \\
\hline Growth $\left(B W^{1}\right)$ slope & 0.13 & \pm 0.02 & 0.09 & 0.16 & 9 \\
\hline Growth $\left(\mathrm{SL}^{2}\right)$ intercept & 4.66 & \pm 0.16 & 4.33 & 4.90 & 9 \\
\hline Growth $\left(\mathrm{SL}^{2}\right)$ slope & 0.05 & \pm 0.02 & 0.04 & 0.09 & 9 \\
\hline
\end{tabular}


498 Table 4. Spearman correlation of egg and larval parameters (only for parameters with one or more

499 significant correlations). Growth characteristics are presented as intercept and slope of the growth curve

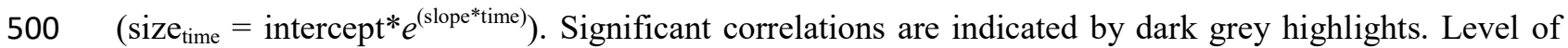

501 significance is indicated by asterisks $(* p<0.05 ; * *<0.01)$.

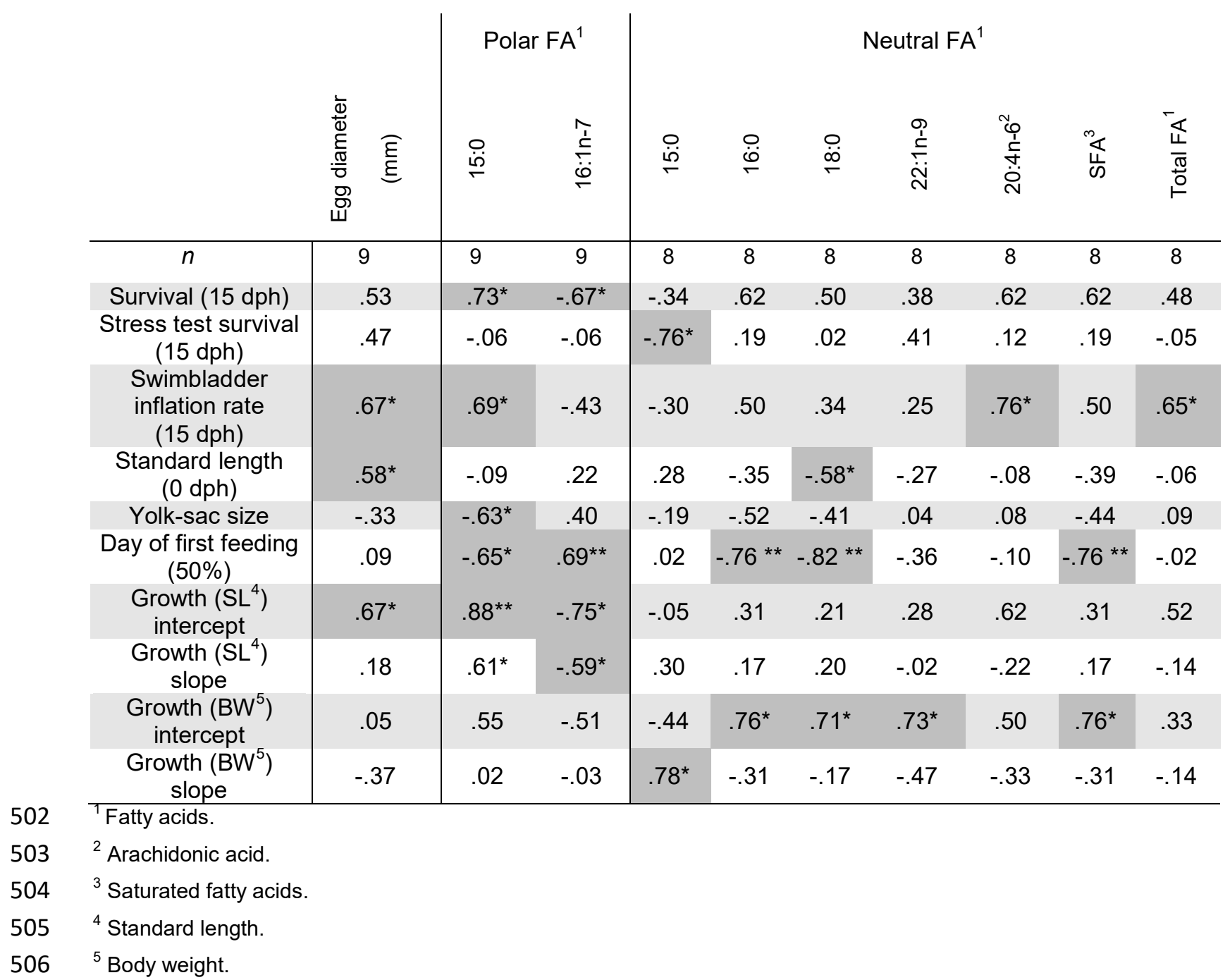

